\title{
Iron supplement use among Danish pregnant women
}

\author{
Vibeke K Knudsen ${ }^{1, *}$, Harald S Hansen ${ }^{2}$, Lars Ovesen ${ }^{3}$, Tina B Mikkelsen ${ }^{1}$ and \\ Sjurður F Olsen ${ }^{1}$ \\ 'Maternal Nutrition Group, Department of Epidemiology Research, Statens Serum Institut, Artillerivej 5, DK-2300 \\ Copenhagen S, Denmark: ${ }^{2}$ Department of Pharmacology, The Danish University of Pharmaceutical Sciences, \\ Universitetsparken 2, DK-2 100 Copenhagen, Denmark: ${ }^{3}$ The Danish Heart Foundation, Hauser Plads 10, DK-1 127 \\ Copenhagen, Denmark
}

Submitted 18 May 2006: Accepted 21 November 2006: First published online 2 March 2007

\begin{abstract}
Objectives: To evaluate compliance with the national recommendation on supplemental iron to all pregnant women in Denmark and to explore differences between compliers and non-compliers with respect to dietary habits and other lifestyle factors.

Design: Intake of supplemental iron from pure iron supplements and from multivitamin and mineral preparations was estimated in mid-pregnancy.

Setting: Nationwide cohort study, the Danish National Birth Cohort (DNBC), comprising more than 100000 women recruited in early pregnancy.

Subjects: Information on diet and dietary supplements was available for 54371 women. Of these, information on lifestyle factors was available for 50902 women. Results: A high compliance with the recommendation was found, as approximately $77 \%$ of the women reported use of iron supplements during pregnancy. However, many of the compliers did not obtain the recommended doses of iron, which can partly be explained by the lack of iron preparations of appropriate doses available on the Danish market. Compliance with the recommendation was associated with age above 20 years, primiparity, body mass index $<30 \mathrm{~kg} \mathrm{~m}^{-2}$, non-smoking and long education. No major differences were seen in dietary intake between compliers and non-compliers.

Conclusion: Overall, a high compliance rate was found among participants of the DNBC but a clarification on daily dose is needed, and more concern should be paid to vulnerable groups such as young, smoking women and women with no or short education.
\end{abstract}

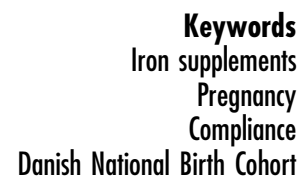

Pregnancy increases the demand for iron in women due to the expanding blood volume of the mother, the increasing maternal supply of iron to the foetus and the considerable iron loss due to blood loss at delivery ${ }^{1}$. It has been reported that approximately $40 \%$ of Danish women of reproductive age have small or absent iron stores ${ }^{2-4}$, i.e. they do not have sufficient iron stores to go through pregnancy without becoming iron-deficient or developing iron-deficiency anaemia. Iron-deficiency anaemia may cause impaired work performance and tiredness, and reduction of immune function ${ }^{5}$. Intervention studies with iron supplementation in pregnancy have shown increased iron stores in the supplemented women compared with non-supplemented women ${ }^{6-11}$, and in two randomised controlled trials the risk of adverse pregnancy outcomes was reduced among the women allocated to iron supplements $^{12,13}$. The Danish National Board of Health's guidelines on pregnancy for health professionals, published in 1998, state that all Danish pregnant women should be advised to take a daily supplement of 50-70 mg iron from week 20 of gestation until delivery ${ }^{14}$. Before 1998, no official recommendation on iron supplement use in relation to pregnancy existed. Until now the adherence to this recommendation has not been examined.

A number of sociodemographic and lifestyle factors have been associated with the use of dietary supplements in general. Socio-economic class is one such factor, with individuals from higher socio-economic groups being more likely to consume dietary supplements than individuals from low socio-economic groups ${ }^{15-21}$. Smoking has also been associated with the use of dietary supplements ${ }^{19,21,22}$ : non-smokers and former smokers being most likely to take supplements. Self-perceived health was associated with the use of dietary supplements in one survey ${ }^{21}$, but not in another ${ }^{18}$, and a wish to improve health has been reported as a reason for taking supplements ${ }^{23}$. Users of supplements are often found to have healthier, more nutrient-dense diets than nonusers $^{18,24,25}$. 
The aims of the present study, conducted within the Danish National Birth Cohort (DNBC), were: (1) to examine how many of the participants took iron supplements during pregnancy; (2) to estimate the amount of iron from supplements; and (3) to describe differences between compliers and non-compliers with the recommendation with respect to gestational, lifestyle and dietary factors.

\section{Materials and methods}

\section{Danish National Birtb Cobort}

Data derive from the DNBC, which is a nationwide birth cohort including more than 100000 pregnant women recruited in early pregnancy in the period from 1997 to 2002. Data were collected through four telephone interviews: in week 12 and week 30 of gestation, and when the child was 6 and 18 months old. Further, all participants received a food-frequency questionnaire (FFQ) in week 25 of gestation, covering diet and use of dietary supplements in mid-pregnancy ${ }^{26}$.

\section{Study population}

Approximately $70 \%$ of the participants returned the FFQ. During the study period, the FFQ was improved several times and not all versions recorded the use of dietary supplements in a reliable way, which reduced the sample size to 58078 observations. Further reductions due to incomplete or erroneous completion of the FFQ left 54371 observations for analyses. Of these, data from telephone interviews were available for 50902 women. All of the women included in the analyses were recruited after the recommendation on iron supplements was implemented.

\section{Iron supplements}

The proportion of women taking iron supplements during pregnancy was assessed using information from the FFQ and the second telephone interview. In the FFQ the women were asked to write the brand name of all supplements, the nutrient content (if single-nutrient supplements) and the number of daily doses taken in the previous four weeks. In the second telephone interview, the women were asked if they had been taking iron supplements during pregnancy ('Have you been taking iron pills during pregnancy?'), and if yes, in which weeks of gestation they had been taking it, ranging from the beginning of pregnancy until the time of interview, which took place around week 30 .

To examine the characteristics of a regular user of iron supplements, a user of supplemental iron was defined as a woman who in the FFQ had reported taking at least one of the above-mentioned iron supplements for at least three out of four days.

\section{Diet}

The FFQ employed in the DNBC was a semi-quantitative 360-item questionnaire, which recorded intake of foods and drinks in the previous four weeks. Intakes of foods and nutrients were calculated by means of the program Foodcalc (www.foodcalc.dk), the Danish food composition tables $^{27}$ and assumptions on standard portion sizes $^{28}$. The FFQ was validated using a 7-day weighed food diary as gold standard, which showed statistically significant correlations between intakes for fruit and vegetables $(r=0.55)$, protein (0.39), folate (0.53) and retinol $(0.37)^{29}$. The differences in dietary habits between users and non-users of iron supplements were examined by comparison of intake of total energy, macronutrients and overall food groups.

\section{Otber factors}

Information on gestational, anthropometric, lifestyle and sociodemographic factors derived from the second telephone interview, conducted in week 30 of gestation. The following factors were regarded as potential determinants of use of iron supplements and included in the analyses: parity ( $0 \mathrm{vs} . \geq 1$ ); whether the pregnancy was planned or not; the woman's age; pre-pregnancy body mass index (BMI); smoking habit during pregnancy; physical activity (yes vs. no) during pregnancy; socioeconomic group (based upon the job description of the woman or her partner, the higher was chosen); housing; whether the woman had a partner or not; whether the woman had worries about her unborn child; the woman's self-perceived health; and alcohol intake in pregnancy (0 vs. $\geq 0.5$ drinks per week).

\section{Statistical analysis}

Differences between women who returned and women who did not return the FFQ were analysed by means of the $\chi^{2}$ test when comparing proportions or the $t$-test for continuous variables. Users of iron supplements were compared with non-users with respect to total energy intake and intake of macronutrients by the $t$-test, and with respect to median dietary intake of selected food groups by use of the Wilcoxon signed rank test as the outcome data were not normally distributed. Possible determinants for use of iron supplements were analysed by means of logistic regression analysis, and odds ratios and 95\% confidence intervals were estimated. All analyses were conducted using SAS version 9.1.3 for Windows (SAS Institute Inc.).

\section{Results}

Women who had completed the FFQ and women who had not completed it, or who had completed it erroneously, were compared with respect to background variables. There were significantly higher proportions of primiparous, normal-weight, non-smoking and physically active women among those who completed the FFQ (and thus were included in the analysis) than among those who did not or completed it erroneously (and thus were excluded 
from the analysis) (Table 1), and more of the included women had planned their pregnancy. The women included in the analyses were slightly older than the women who were excluded.

From information on brand names recorded in the FFQ, iron supplements were defined as pure iron supplements, liquid iron supplements and supplements with haem iron. Seventy-seven per cent of the women reported use of iron supplements in the FFQ, irrespective of dose ingested (Table 2). This is in accordance with the results from the second interview, as approximately three-quarters of the participants reported taking iron supplements from week 20 of gestation as recommended, see Fig. 1 (the small decrease in the proportion of women taking supplements from week 28 onwards is due to missing information, as a small proportion of the participants were interviewed before week 30 of gestation).

The dietary patterns among users and non-users of iron supplements are shown in Table 3. No statistically significant difference was seen in daily energy intake or intake of macronutrients. With respect to food groups, supplement users had significantly higher intakes of fruit and poultry, while non-users had slightly higher intake of cereals than users. However, although statistically significant, the differences were small.

The gestational and lifestyle factors that were regarded as potential determinants for use of iron supplements were analysed in univariate models. Furthermore, all explanatory variables were included in a multiple logistic regression model, with use and non-use of supplemental iron as the outcome variable. The results are shown in Table 4. The woman's age, BMI, parity, planning of pregnancy, smoking habits, alcohol habits and physical activity in pregnancy were associated with use of supplemental iron, with primiparous, normal-weight, non-smoking, physically active women above the age of 20 years with planned pregnancies having the highest

Table 1 Comparison of women who were included vs. not included in the analyses $(N=101068)$

\begin{tabular}{lccc}
\hline & $\begin{array}{c}\text { Women included } \\
\text { in analyses } \\
(n=51151)^{\star}\end{array}$ & $\begin{array}{c}\text { Women not included } \\
\text { in analyses } \\
(n=37700)^{\star}\end{array}$ & $P$-value \\
\hline $\begin{array}{l}\text { Primiparous (\%) } \\
\text { Planned }\end{array}$ & 50.2 & 42.8 & $<0.0001 \ddagger$ \\
$\quad \begin{array}{l}\text { pregnancy (\%) } \\
\text { Normal }\end{array}$ & 77.3 & 74.1 & $<0.0001 \ddagger$ \\
$\quad$ weight† (\%) & 63.3 & 54.0 & $<0.0001 \ddagger$ \\
$\begin{array}{l}\text { Non-smokers (\%) } \\
\text { Physically } \\
\text { active (\%) }\end{array}$ & 76.3 & 70.2 & $<0.0001 \ddagger$ \\
$\begin{array}{c}\text { Age (years), } \\
\text { mean (SD) }\end{array}$ & 37.7 & 34.8 & $<0.0001 \ddagger$ \\
\hline
\end{tabular}

SD - standard deviation.

* Not all women participated in the telephone interviews, thus the sum is not equal to 101068 .

$\dagger$ Body mass index $=25-29 \mathrm{~kg} \mathrm{~m}^{-2}$.

$\ddagger \chi^{2}$ test.

$\S t$-test.
Table 2 Intake of iron supplements in the Danish National Birth Cohort $(N=54371)^{\star}$

\begin{tabular}{lc}
\hline & $n(\%)$ \\
\hline Women who took iron supplements & $41971(77.2)$ \\
$75 \%$ complier† & $35325(65.0)$ \\
Daily iron dose & \\
$0 \mathrm{mg}$ & $12400(22.8)$ \\
$1-49 \mathrm{mg}$ & $16543(30.4)$ \\
$50-70 \mathrm{mg}$ & $5355(9.9)$ \\
$71-100 \mathrm{mg}$ & $18892(34.8)$ \\
$>101 \mathrm{mg}$ & $1181(2.2)$ \\
Iron formulations used & \\
Liquid iron formulations & $3778(7.0)$ \\
Haem iron & $12052(22.2)$ \\
Low-dose $(1-27 \mathrm{mg})$ & $7048(13.0)$ \\
High-dose $(30-100 \mathrm{mg})$ & $20001(36.8)$
\end{tabular}

* Data are based on information from the food-frequency questionnaire, covering intake in weeks $21-25$ of gestation.

† $75 \%$ complier - women who took iron supplements for a minimum of $75 \%$ of the recording time (four weeks).

¥The sum of all formulations used is higher than the number of women who reported taking iron supplements, as a small number of women reported use of more than one iron supplement.

probability of taking iron supplements. The estimates were slightly weakened after adjusting for the other factors. Compared with the unemployed, all other socioeconomic groups had a higher probability of taking iron supplements in the univariate analyses. The association was weakened in the adjusted analysis. In the univariate analysis women who perceived their health as good had a higher probability of taking iron supplements than the women who reported having less good health; the association was weakened in the adjusted analysis. No clear association could be established between use of supplements and the woman's worry about the unborn child. No associations were seen between civil status or housing and use of iron supplements. Women who drank alcohol ( $\geq 0.5$ drinks per week) during their pregnancy had a lower probability of taking iron compared with women who abstained from alcohol during pregnancy.

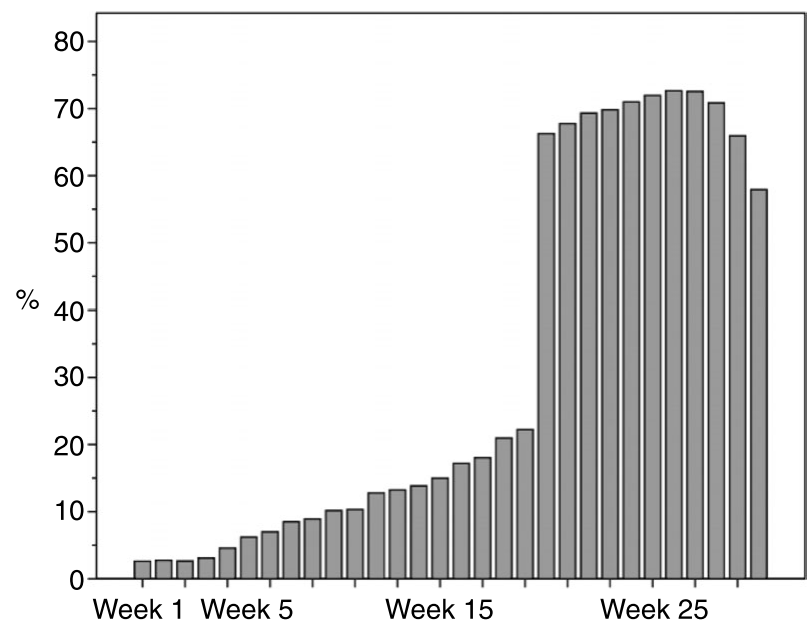

Fig. 1 Proportion of women (\%) reporting intake of iron supplements on a weekly basis in each week of gestation from week 1 to week 30 
Table 3 Intakes of energy, macronutrients and food groups in users (at least $75 \%$ of daily doses) and non-users of supplemental iron $(N=54371)$

\begin{tabular}{lccc}
\hline & Non-users $(n=19047)$ & Users $(n=35324)$ & $P$-value \\
\hline Total energy (kJ) & $9903(2432)$ & $9931(2374)$ & $0.3962^{*}$ \\
Protein (\% of energy) & $15.1(2.4)$ & $15.3(2.4)$ & $0.2723^{*}$ \\
Carbohydrate (\% of energy) & $53.8(6.0)$ & $54.4(5.9)$ & $0.7987^{*}$ \\
Fat (\% of energy) & $30.6(6.2)$ & $29.8(5.9)$ & $0.5217^{*}$ \\
Alcohol (\% of energy) & $0.50(0.7)$ & $0.45(0.6)$ & $0.1205^{*}$ \\
Dietary variables (g/10 MJ) & & & \\
$\quad$ Dairy products & $608(377 ; 829)$ & $607(374 ; 833)$ & $0.6113 \dagger$ \\
Fruit & $277(156 ; 424)$ & $280(159 ; 429)$ & $0.0224 \dagger$ \\
Vegetables & $104(69 ; 155)$ & $105(69 ; 157)$ & $0.3371 \dagger$ \\
Meat & $85(64 ; 108)$ & $84(64 ; 108)$ & $0.5436 \dagger$ \\
Fish & $22(12 ; 34)$ & $22(13 ; 34)$ & $0.1219 \dagger$ \\
Poultry & $21(12 ; 32)$ & $22(12 ; 33)$ & $0.0010 \dagger$ \\
Cereals & $271(221 ; 322)$ & $270(220 ; 321)$ & $0.0689 \dagger$ \\
Potatoes & $104(70 ; 153)$ & $103(70 ; 152)$ & $0.1297 \dagger$ \\
Fats & $28(19 ; 39)$ & $28(19 ; 39)$ & $0.5348 \dagger$ \\
\hline
\end{tabular}

Data are presented as mean (standard deviation) or median (25th percentile; 75th percentile).

${ }^{*} t$-test.

†Wilcoxon signed rank test.

\section{Discussion}

More than two-thirds of the participants reported use of iron supplements after week 20 of gestation, which shows that the recommendation on use of iron supplements has to a great extent reached the target group within this population.

We found a lower likelihood of compliance with the recommendation for iron supplementation among young, overweight, physically inactive, smoking women, who had not planned their pregnancy. Young age has been associated with low compliance to health campaigns in earlier studies ${ }^{30,31}$, indicating that younger individuals are less conscious about health matters or simply do not receive the message. Smoking in pregnancy was previously found to be associated with a low rate of iron supplementation ${ }^{16,22}$, which is supported by results from two surveys where pregnant smokers were found to have a less healthy diet than non-smokers ${ }^{32,33}$. In two more surveys in non-pregnant populations, the former smokers were most likely to take dietary supplements ${ }^{19,21}$, while another survey found no association between supplement use and smoking habit ${ }^{17}$. Smokers may to a high degree belong to a group who care less about their health or they are not reached by public health campaigns. Overweight women also represented a group of individuals who to a lesser degree followed the official guidelines according to iron supplement use, which is also supported by earlier findings ${ }^{16,30}$. Not surprisingly, the women who had planned their pregnancy were more likely to follow the recommendations, and may be regarded as more conscious about their pregnancy. Multiparous women were less likely to follow the recommendations and the difference remained after adjusting for age. This was also seen in a previous study of compliance with a recommendation of periconceptional folic acid supplementation $^{31}$ and indicates that multiparous women may have a more casual attitude towards health matters in relation to pregnancy, possibly because the majority have experienced a previously uncomplicated pregnancy.

We found a clear association between socio-economic class and use of iron supplements, with a higher proportion of iron users among the well-educated women. This is confirmed in several studies, where populations with longer education were more likely to take dietary supplements than groups of less-privileged individuals ${ }^{15-21,30,33}$. This is also somewhat supported in two surveys where low educational level was found to be associated with low haemoglobin concentration in pregnancy $^{34,35}$.

The differences in dietary intake between users and non-users were small and reached statistical significance in only two cases, and thus were probably not of nutritional importance. However, the difference may give a picture of the dietary patterns of users and non-users of iron supplements pointing towards the fact that users of supplements to a higher extent eat a diet closer to current recommendations. This is supported by earlier findings in non-pregnant individuals, showing that users of dietary supplements in general have a healthier diet than nonusers, and that individuals who take dietary supplements are the most unlikely to need them ${ }^{18,24}$.

A large proportion of the women took iron supplements in low doses and consequently did not meet the recommended dose of 50-70 mg iron per day. In contrast, many of the women took twice the recommended daily dosage or more per day. Many of the iron preparations available on the Danish market contain $100 \mathrm{mg}$ iron per tablet, and only a few of the iron preparations recorded in this cohort contained iron in the recommended dose, 50-70 mg. This makes it difficult for women to follow the recommendation. As a consequence, many of the pregnant women were exposed to high doses of iron; this is considered unfavourable as excess iron intake may 
Table 4 Determinants of use (at least $75 \%$ of daily doses, $n=33145)$ vs. non-use ( $n=17757)$ of iron supplements $(N=50902)$

\begin{tabular}{|c|c|c|c|c|}
\hline & \multirow[b]{2}{*}{$n$} & \multirow[b]{2}{*}{$\%$} & \multicolumn{2}{|c|}{ OR $(95 \% \mathrm{Cl})$} \\
\hline & & & Univariate & Multivariate \\
\hline \multicolumn{5}{|l|}{ Parity } \\
\hline 0 & 25570 & 70.0 & $1.51(1.45-1.57)$ & $1.50(1.44-1.56)$ \\
\hline$\geq 1$ & 25332 & 60.3 & 1.00 (referent) & 1.00 (referent) \\
\hline \multicolumn{5}{|l|}{ Planned pregnancy } \\
\hline Planned & 38385 & 66.4 & $1.39(1.31-1.47)$ & $1.25(1.17-1.33)$ \\
\hline Partly planned & 6245 & 62.1 & $1.14(1.06-1.23)$ & $1.05(0.98-1.14)$ \\
\hline Not planned & 5272 & 58.4 & 1.00 (referent) & 1.00 (referent) \\
\hline \multicolumn{5}{|l|}{ Woman's age (years) } \\
\hline$<20$ & 392 & 48.2 & $0.49(0.41-0.60)$ & $0.56(0.46-0.69)$ \\
\hline $20-29$ & 27765 & 66.7 & 1.00 (referent) & 1.00 (referent) \\
\hline $30-39$ & 22257 & 63.5 & $0.88(0.85-0.92)$ & $1.00(0.96-1.04)$ \\
\hline$>40$ & 488 & 64.3 & $0.93(0.77-1.12)$ & $1.16(0.96-1.41)$ \\
\hline \multicolumn{5}{|l|}{ Pre-pregnancy BMI $\left(\mathrm{kg} \mathrm{m}^{-2}\right)$} \\
\hline$<18.5$ & 2837 & 63.8 & $0.90(0.84-0.98)$ & $0.95(0.88-1.03)$ \\
\hline $18.6-24.9$ & 33789 & 66.0 & 1.00 (referent) & 1.00 (referent) \\
\hline $25.0-29.9$ & 9996 & 64.6 & $0.96(0.91-1.00)$ & $0.98(0.93-1.02)$ \\
\hline $30.0-34.9$ & 3120 & 60.9 & $0.81(0.75-0.87)$ & $0.83(0.77-0.90)$ \\
\hline$\geq 35.0$ & 1160 & 59.1 & $0.75(0.66-0.84)$ & $0.78(0.69-0.88)$ \\
\hline \multicolumn{5}{|l|}{ Smoking habit in pregnancy } \\
\hline Non-smoker & 38698 & 66.3 & 1.00 (referent) & 1.00 (referent) \\
\hline Former and occasional smoker & 6454 & 64.4 & $0.92(0.87-0.97)$ & $0.91(0.86-0.96)$ \\
\hline$<15$ cigarettes per day & 4890 & 58.9 & $0.73(0.69-0.78)$ & $0.79(0.74-0.84)$ \\
\hline$>15$ cigarettes per day & 860 & 53.4 & $0.58(0.51-0.66)$ & $0.70(0.61-0.81)$ \\
\hline \multicolumn{5}{|l|}{ Alcohol intake in pregnancy } \\
\hline 0 & 27656 & 63.7 & $1.07(1.04-1.11)$ & $1.08(1.04-1.12)$ \\
\hline$\geq 0.5$ drinks per week & 23246 & 62.0 & 1.00 (referent) & 1.00 (referent) \\
\hline \multicolumn{5}{|l|}{ Physical activity in pregnancy } \\
\hline Yes & 19186 & 64.8 & $1.14(1.10-1.18)$ & $1.03(0.99-1.08)$ \\
\hline \multirow{2}{*}{\multicolumn{5}{|c|}{ Socio-economic group }} \\
\hline & & & & \\
\hline High & 12280 & 63.6 & $1.70(1.47-1.95)$ & $1.36(1.17-1.58)$ \\
\hline Medium & 16218 & 65.4 & $1.83(1.59-2.10)$ & $1.47(1.27-1.71)$ \\
\hline Skilled & 13770 & 62.2 & $1.60(1.39-1.83)$ & $1.34(1.15-1.55)$ \\
\hline Unskilled & 6216 & 59.3 & $1.41(1.22-1.63)$ & $1.25(1.07-1.45)$ \\
\hline Student & 1617 & 60.8 & $1.50(1.27-1.78)$ & $1.18(1.00-1.41)$ \\
\hline Unemployed & 801 & 50.8 & 1.00 (referent) & 1.00 (referent) \\
\hline \multicolumn{5}{|l|}{ Housing } \\
\hline Own residence & 13884 & 63.3 & $1.02(0.98-1.06)$ & $1.01(0.97-1.05)$ \\
\hline Rent & 36784 & 62.9 & 1.00 (referent) & 1.00 (referent) \\
\hline Without residence & 234 & 53.1 & $0.67(0.52-0.86)$ & $0.81(0.62-1.05)$ \\
\hline \multicolumn{5}{|l|}{ Civil status, has a partner } \\
\hline Yes & 50039 & 63.1 & $1.34(1.18-1.54)$ & $0.99(0.85-1.15)$ \\
\hline No & 863 & 55.9 & 1.00 (referent) & 1.00 (referent) \\
\hline \multicolumn{5}{|l|}{ Worry about unborn child } \\
\hline Not at all & 8010 & 60.0 & $0.91(0.86-0.96)$ & $0.93(0.88-0.99)$ \\
\hline Little & 30154 & 64.0 & $1.08(1.03-1.12)$ & $1.05(1.01-1.10)$ \\
\hline Very much & 12738 & 62.3 & 1.00 (referent) & 1.00 (referent) \\
\hline \multicolumn{5}{|l|}{ Woman's self-perceived health } \\
\hline Very good & 27058 & 63.4 & $1.29(1.17-1.42)$ & $1.10(0.99-1.21)$ \\
\hline Average & 22051 & 62.9 & $1.26(1.14-1.39)$ & $1.13(1.03-1.25)$ \\
\hline Not so good & 1793 & 57.3 & 1.00 (referent) & 1.00 (referent) \\
\hline
\end{tabular}

OR - odds ratio; $\mathrm{Cl}$ - confidence interval; BMI - body mass index.

lead to increased oxidative stress, which has been associated with gestational hypertension ${ }^{36}$ and increased risk of cancer ${ }^{37}$. Furthermore, high intakes of iron impair absorption of zinc and other metal ions ${ }^{38}$ which are also of increased need during pregnancy ${ }^{39}$. The prevalence of hereditary haemochromatosis, which is characterised by high intestinal iron absorption, is $0.25 \%$ for the homozygotic mutation and $9.2 \%$ for the heterozygotic mutation $^{40}$, and pregnant women having this condition should be cautious about taking the high-dose iron supplements.

In a Swedish survey of adherence to recommendations on iron supplements in pregnancy, side-effects of the supplements (gastrointestinal problems) were mentioned as a reason for poor compliance, as the recommended daily dose was high $(100 \mathrm{mg})$ and side-effects of the supplements were reported to be dose-dependent ${ }^{41}$. On the other hand, in a randomised controlled trial with iron 
supplements in varying doses, no difference in occurrence of side-effects was reported in the groups who received 20, 40, 60 or $80 \mathrm{mg}$ iron per day ${ }^{42}$. However, this may be a reason for not taking iron supplements, as many of the available products contain $100 \mathrm{mg}$ iron per daily dosage.

The strengths of this study are the large number of participants and the wide variety of information on lifestyle and sociodemographic factors collected routinely in DNBC. A limitation of the cohort is that the participants cannot be regarded as representative for the whole population of Danish pregnant women ${ }^{26}$. The latter is assumed to cause a selection of women in the cohort who are more concerned about health matters in relation to pregnancy compared with the background population ${ }^{43}$. The proportions of iron supplement users found in this study must therefore be regarded as being overestimated, if not representative. However, the results from this study indicate that pregnant women belong to a group who in general pays attention to health recommendations.

Responders and non-responders to FFQs are often found to differ with respect to lifestyle variables such as smoking and $\mathrm{BMI}^{44}$. This was also the case in this study, as seen in Table 1. However, even though the women included in these analyses may not be representative, we do believe that the patterns in differences between users and non-users of iron supplements may reflect the patterns in the background population.

\section{Conclusion}

The recommendation for pregnant women to take supplemental iron from week 20 of gestation has been met with success although the doses taken are not optimal. Many pregnant women take iron in excess of recommended levels due to inappropriate product formulations on the Danish market. Not surprisingly, well-educated, non-smoking women above 20 years of age comply with the recommendations to a higher degree than young smoking women with short or no education. In the future, campaigns should be aimed at more vulnerable groups, and more attention should be paid to ensure availability of supplements with appropriate doses of iron on the Danish market.

\section{Acknowledgements}

Sources of funding: The DNBC was funded by the Danish National Research Foundation, March of Dimes Birth Defects Foundation, Pharmacy Foundation, Egmont Foundation, Augustinus Foundation, the Health Foundation and the European Union (QLK1-2000-00 083). The DNBC managerial team consisted of Jørn Olsen (chair), Mads Melbye, Anne Marie Nyboe Andersen, Sjurdur F Olsen, Thorkild IA Sørensen and Peter Aabye.

Conflict of interest declaration: None of the authors had any conflicts of interest.
Authorship responsibilities: V.K.K., H.S.H., L.O. and S.F.O. were involved in generating the purpose of the work. V.K.K. was involved in data collection, analysing and interpreting data, and writing the manuscript. H.S.H., L.O. and S.F.O. were involved in interpreting the data and editing the manuscript. T.B.M. was involved in data collection, interpreting the data and editing the manuscript.

\section{References}

1 Bothwell TH. Iron requirements in pregnancy and strategies to meet them. American Journal of Clinical Nutrition 2000; 72: $257 \mathrm{~S}-64 \mathrm{~S}$.

2 Milman N, Rosdahl N, Lyhne N, Jorgensen T, Graudal N. Iron status in Danish women aged 35-65 years. Relation to menstruation and method of contraception. Acta Obstetricia et Gynecologica Scandinavica 1993; 72: 601-5.

3 Milman N, Clausen J, Byg KE. Iron status in 268 Danish women aged 18-30 years: influence of menstruation, contraceptive method, and iron supplementation. Annals of Hematology 1998; 77: 13-9.

4 Milman N, Byg KE, Ovesen L, Kirchhoff M, Jurgensen KS. Iron status in Danish women, 1984-1994: a cohort comparison of changes in iron stores and the prevalence of iron deficiency and iron overload. European Journal of Haematology 2003; 71: 51-61.

5 Baynes RD. Iron deficiency. In: Brock JH, Halliday JW, Pippard MJ, Powell LW, eds. Iron Metabolism in Health and Disease. London: WB Saunders Company Ltd, 1994; 189-226.

6 Milman N, Agger AO, Nielsen OJ. Iron supplementation during pregnancy. Effect on iron status markers, serum erythropoietin and human placental lactogen. A placebo controlled study in 207 Danish women. Danish Medical Bulletin 1991; 38: 471-6.

7 Meier PR, Nickerson HJ, Olson KA, Berg RL, Meyer JA. Prevention of iron deficiency anemia in adolescent and adult pregnancies. Clinical Medicine \& Research 2003; 1: 29-36.

8 Menendez C, Todd J, Alonso PL, Francis N, Lulat S, Ceesay S, et al. The effects of iron supplementation during pregnancy, given by traditional birth attendants, on the prevalence of anaemia and malaria. Transactions of the Royal Society of Tropical Medicine and Hygiene 1994; 88: 590-3.

9 Simmons WK, Cook JD, Bingham KC, Thomas M, Jackson J, Jackson $\mathrm{M}$, et al. Evaluation of a gastric delivery system for iron supplementation in pregnancy. American Journal of Clinical Nutrition 1993; 58: 622-6.

10 Doyle W, Srivastava A, Crawford MA, Bhatti R, Brooke Z, Costeloe KL. Inter-pregnancy folate and iron status of women in an inner-city population. British Journal of Nutrition 2001; 86: 81-7.

11 Makrides M, Crowther CA, Gibson RA, Gibson RS, Skeaff CM. Efficacy and tolerability of low-dose iron supplements during pregnancy: a randomized controlled trial. American Journal of Clinical Nutrition 2003; 78: 145-53.

12 Cogswell ME, Parvanta I, Ickes L, Yip R, Brittenham GM. Iron supplementation during pregnancy, anemia, and birth weight: a randomized controlled trial. American Journal of Clinical Nutrition 2003; 78: 773-81.

13 Siega-Riz AM, Hartzema AG, Turnbull C, Thorp J, McDonald T, Cogswell ME. The effects of prophylactic iron given in prenatal supplements on iron status and birth outcomes: a randomized controlled trial. American Journal of Obstetrics and Gynecology 2006; 194: 512-9. 
14 Sundhedsstyrelsen (National Board of Health). Svangreomsorg. Retningslinier og redegørelse [Guidelines for Prenatal Care]. Copenhagen: Sundhedsstyrelsen, 1998.

15 Cogswell ME, Kettel-Khan L, Ramakrishnan U. Iron supplement use among women in the United States: science, policy and practice. Journal of Nutrition 2003; 133: 1974 S-7S.

16 Nordeng H, Eskild A, Nesheim BI, Aursnes I, Jacobsen G. Guidelines for iron supplementation in pregnancy: compliance among 431 parous Scandinavian women. European Journal of Clinical Pharmacology 2003; 59: 163-8.

17 Block G, Cox C, Madans J, Schreiber GB, Licitra L, Melia N. Vitamin supplement use, by demographic characteristics. American Journal of Epidemiology 1988; 127: 297-309.

18 Lyle BJ, Mares-Perlman JA, Klein BE, Klein R, Greger JL. Supplement users differ from nonusers in demographic, lifestyle, dietary and health characteristics. Journal of Nutrition 1998; 128: 2355-62.

19 Subar AF, Block G. Use of vitamin and mineral supplements: demographics and amounts of nutrients consumed. The 1987 Health Interview Survey. American Journal of Epidemiology 1990; 132: 1091-101.

20 Wallstrom P, Elmstahl S, Hanson BS, Ostergren PO, Johansson U, Janzon L, et al. Demographic and psychosocial characteristics of middle-aged women and men who use dietary supplements. European Journal of Public Health 1996; 6: 188-95.

21 Knudsen VK, Rasmussen LB, Haraldsdottir J, Ovesen L, Bulow I, Knudsen N, et al. Use of dietary supplements in Denmark is associated with health and former smoking. Public Health Nutrition 2002; 5: 463-8.

22 Haslam C, Lawrence W. Health-related behavior and beliefs of pregnant smokers. Health Psychology 2004; 23: 486-91.

23 Overvad K, Diamant B, Holm L, Holmer G, Mortensen SA, Stender S. Coenzyme Q10 in health and disease. European Journal of Clinical Nutrition 1999; 53: 764-70.

24 Beitz R, Mensink GB, Hintzpeter B, Fischer B, Erbersdobler HF. Do users of dietary supplements differ from nonusers in their food consumption? European Journal of Epidemiology 2004; 19: 335-41.

25 Elmstahl S, Wallstrom P, Berglund G, Janzon L, Johansson U, Larson SA, et al. The use of dietary supplements in relation to dietary habits in a Swedish middle-aged population. Scandinavian Journal of Nutrition 1994; 38: 94-7.

26 Olsen J, Melbye M, Olsen SF, Sorensen TI, Aaby P, Andersen AM, et al. The Danish National Birth Cohort - its background, structure and aim. Scandinavian Journal of Public Health 2001; 29: 300-7.

27 Levnedsmiddelstyrelsen (National Food Agency of Denmark). Levnedsmiddeltabeller [The Composition of Foods]. Søborg: Levnedsmiddelstyrelsen, 1996.

28 Andersen LT, Jensen H, Haraldsdottir J. Typical weights for food items. Scandinavian Journal of Nutrition 1996; 40 : S129-52.

29 Mikkelsen TB, Osler M, Olsen SF. Validity of protein, retinol, folic acid and $n-3$ fatty acid intakes estimated from the food-frequency questionnaire used in the Danish National Birth Cohort. Public Health Nutrition 2006; 9: 771-8.

30 Erkkola M, Karppinen M, Jarvinen A, Knip M, Virtanen SM. Folate, vitamin D, and iron intakes are low among pregnant Finnish women. European Journal of Clinical Nutrition 1998; 52: 742-8.

31 Knudsen VK, Orozova-Bekkevold I, Rasmussen LB, Mikkelsen TB, Michaelsen KF, Olsen SF. Low compliance with recommendations on folic acid use in relation to pregnancy: is there a need for fortification? Public Health Nutrition 2004; 7: $843-50$.

32 Trygg K, Lund Larsen K, Sandstad B, Hoffman HJ, Jacobsen G, Bakketeig LS. Do pregnant smokers eat differently from pregnant non-smokers? Paediatric and Perinatal Epidemiology 1995; 9: 307-19.

33 Mathews F, Yudkin P, Smith RF, Neil A. Nutrient intakes during pregnancy: the influence of smoking status and age. Journal of Epidemiology and Community Health 2000; 54 : $17-23$.

34 Bergmann RL, Gravens-Muller L, Hertwig K, Hinkel J, Andres $\mathrm{B}$, Bergmann $\mathrm{KE}$, et al. Iron deficiency is prevalent in a sample of pregnant women at delivery in Germany. European Journal of Obstetrics, Gynecology, and Reproductive Biology 2002; 102: 155-60.

35 Bodnar LM, Siega-Riz AM, Arab L, Chantala K, McDonald T. Predictors of pregnancy and postpartum haemoglobin concentrations in low-income women. Public Health Nutrition 2004; 7: 701-11.

36 Casanueva E, Viteri FE. Iron and oxidative stress in pregnancy. Journal of Nutrition 2003; 133: 1700S-8S.

37 Fisher AE, Naughton DP. Iron supplements: the quick fix with long-term consequences. Nutrition Journal 2004; 3: 2.

38 Sandstrom B. Micronutrient interactions: effects on absorption and bioavailability. British Journal of Nutrition 2001; 85(Suppl. 2): S181-5.

39 Scholl TO, Hediger ML, Schall JI, Fischer RL, Khoo CS. Low zinc intake during pregnancy: its association with preterm and very preterm delivery. American Journal of Epidemiology 1993; 137: 1115-24.

40 Ellervik C, Mandrup-Poulsen T, Nordestgaard BG, Larsen LE, Appleyard M, Frandsen M, et al. Prevalence of hereditary haemochromatosis in late-onset type 1 diabetes mellitus: a retrospective study. Lancet 2001; 358: 1405-9.

41 Wulff M, Ekstrom EC. Iron supplementation during pregnancy in Sweden: to what extent is the national recommendation followed? Acta Obstetricia et Gynecologica Scandinavica 2003; 82: 628-35.

42 Milman N, Bergholt T, Eriksen L, Byg KE, Graudal N, Pedersen $\mathrm{P}$, et al. Iron prophylaxis during pregnancy - how much iron is needed? A randomized dose-response study of 20-80 $\mathrm{mg}$ ferrous iron daily in pregnant women. Acta Obstetricia et Gynecologica Scandinavica 2005; 84: 238-47.

43 Hennekens CH, Buring JE. Epidemiology in Medicine. Boston, MA: Little, Brown and Company, 1987.

44 Margetts BM, Nelson M. Design Concepts in Nutritional Epidemiology. Oxford: Oxford University Press, 1991. 